IFN Working Paper No. 875, 2011

\title{
Are Married Spouses Insured by their Partners' Social Insurance?
}

Martin Olsson and Peter Skogman Thoursie 


\title{
Are Married Spouses Insured by their Partners' Social Insurance?*
}

\author{
Martin Olsson` and Peter Skogman Thoursie*
}

\begin{abstract}
We use a Swedish sickness insurance reform to show that among married couples a partner's benefit level affects spousal labour supply. The spousal elasticity of sick days with respect to the partner's benefit is estimated to be 0.4 , which is about one-fourth of the own labor supply elasticity. It is argued the main part of this effect is an insurance income effect.
\end{abstract}

Keywords: Spousal labor supply, spill-over, social insurance programs.

JEL-Codes: D10; J13; J22

\footnotetext{
* This version is based on the former IFAU-report "Insured by the partner?".The authors are grateful for comments by Peter Fredriksson, Ethan Kaplan, Rafael Lalive, Mårten Palme, Lars Persson, Per PetterssonLidbom, Emilia Simeonova and Johan Vikström, as well as participants at the 2009 SUDSWEc conference in Uppsala. Martin Olsson is grateful for financial support from the Jan Wallander and Tom Hedelius Foundation. ^Department of Economics, Stockholm University, S-10691 Stockholm, Sweden; Institute for Labour Market Policy Evaluation (IFAU), S-75120, Uppsala, Sweden; Research Institute of Industrial Economics (IFN); email: martin.olsson@ne.su.se.

* Department of Economics, Stockholm University, S-10691 Stockholm, Sweden; Institute for Labour Market Policy Evaluation (IFAU), S-75120, Uppsala, Sweden; email: Peter.Thoursie@ifau.uu.se.
} 


\section{Introduction}

The disincentive effects of social insurance systems on individual labour supply are well documented, but knowledge how they affect family labour supply is scarcer. We use a Swedish reform in the sickness insurance system to investigate if an increase in a partner's benefit level spills over to spousal labour supply. In theory, for couples with a common household budget such an effect operates through an income effect which consists of three components: 1) an insurance income effect which arises since the partner's higher benefit level alters the cost of future illness by the partner. ${ }^{1}$ If leisure is a normal good this will increase spousal sick reporting regardless of whether the partner directly reacts to the reform; 2) a direct income effect since an increased benefit level can change the partner's sick reporting and thus also his/her earnings. The sign of this effect is a priori unknown since the partner's earnings change can go in either direction, and 3) a joint leisure effect that occurs if a couple wants to spend more leisure time together. ${ }^{2}$ Decomposing a disincentive effect into different mechanism has proven to be empirically difficult (Autor and Duggan 2007).

To date results indicate that partners' sickness insurance spill over to spousal labor supply; the spousal elasticity of sick days with respect to the partner's benefit is estimated to 0.36 (own labour supply elasticity in the unemployment insurance is close to 1; see Krueger and Meyer 2002). The major part of this effect is an insurance income effect.

\section{The reform and data}

Sweden has a compulsory publicly administered sickness insurance program funded primarily through a payroll tax levied on employers. Income compensation constitutes the major part of this program, though the replacement rate has varied over time. In December 1987 it was increased for spells lasting less than a week and the waiting day was abolished. For details of the current system and the 1987 reform, see Pettersson-Lidbom and Skogman Thoursie (2010).

Central government workers (16 percent of the workforce) were not affected by the reform in 1987, having a 92 percent replacement rate before and after the reform. In contrast,

\footnotetext{
${ }^{1}$ This is related to the added-worker effect studied in the unemployment insurance literature. A central thesis explored is the degree to which the incentive for the spouse to increase labour supply when the partner becomes unemployed diminishes with the partner's unemployment benefit level (see Ashenfelter 1980, Heckman and MaCurdy 1980, and Lundberg 1985). Cullen and Gruber (2000) find that the labour supply of wives to unemployed husbands is affected by the husbands' unemployment insurance.

${ }^{2}$ Or that spousal sick reporting decreases if the partner increases his/her sick reporting and can do more of the household work.
} 
after the reform for local government workers (39 percent) compensation increased from 90 to 100 percent. Unfortunately, the exact increase for workers in the private sector (45 percent) is unknown because the pre-replacement rate was based on job characteristics and collective agreements not available to us.

We match information on start- and end dates for all sick spells in Sweden from the Swedish National Insurance Board with information from the register LINDA, a representative register data set covering 3.3 percent of the Swedish population. ${ }^{3}$ The data set analyzed exclusively treats married workers employed in the central governmental sector from 1986 to 1990 using a difference-in-difference estimator. ${ }^{4}$ Treated are spouses to partners who were affected by the reform; untreated are spouses to partners who were unaffected by the reform. The sample includes individuals married to partners who were affected by the reform, excluding individuals married to partners who were not affected. The final sample is an unbalanced panel of all 18,819 individuals observed in 1986, with an average occurrence of 3.35 years. Table 1 displays average values by group before and after the reform. No effect is found for the incidence, but durations are prolonged. No big compositional changes are found, only age showing a slight increase after the reform. ${ }^{5}$

Table 1. Average values for treatment and control group before and after the reform

\begin{tabular}{lccccc}
\hline & $\begin{array}{c}\text { After } \\
(1)\end{array}$ & $\begin{array}{c}\text { Before } \\
(2)\end{array}$ & $\begin{array}{c}\text { After } \\
(3)\end{array}$ & $\begin{array}{c}\text { Before } \\
(4)\end{array}$ & $\begin{array}{c}\text { DD } \\
(1)-(2)-[(3)-(4)]\end{array}$ \\
\hline Individual sample & & & & & \\
Yearly incidence & 0.68 & 0.65 & 0.71 & 0.68 & 0.01 \\
& $(0.46)$ & $(0.48)$ & $(0.46)$ & $(0.47)$ & $(0.01)$ \\
Observations & 27821 & 26045 & 8516 & 7897 & \\
\hline Positive spells & & & & & \\
Log duration & 1.14 & 1.12 & 1.13 & 1.14 & 0.04 \\
& $(1.00)$ & $(1.01)$ & $(1.02)$ & $(1.03)$ & $(0.16)$ \\
Family size & 3.37 & 3.44 & 3.31 & 3.34 & -0.028 \\
& $(1.09)$ & $(1.06)$ & $(1.07)$ & $(1.07)$ & $(0.02)$ \\
Wives & 0.43 & 0.42 & 0.58 & 0.58 & 0.01 \\
& $(0.50)$ & $(0.49)$ & $(0.49)$ & $(0.49)$ & $(0.01)$ \\
Urban & 0.38 & 0.40 & 0.37 & 0.40 & 0.01 \\
& $(0.49)$ & $(0.49)$ & $(0.48)$ & $(0.49)$ & $(0.01)$ \\
Age & 44.31 & 42.33 & 44.46 & 42.81 & 0.34 \\
Spells & $(8.20)$ & $(8.75)$ & $(8.21)$ & $(9.16)$ & $(0.18)$ \\
\hline
\end{tabular}

Notes: Columns (1)-(4) report standard deviations in parentheses. For the DD-estimates, OLS standard errors clustered on individuals are displayed in parentheses. Duration is right censored at 50 days and measured in logs to deal with outliers.

\footnotetext{
${ }^{3}$ See Edin and Fredriksson (2000) for a general description of LINDA.

${ }^{4}$ We necessarily limit the analysis to individuals aged 20-64 with a yearly income above SEK 6000, since workers with less cannot claim insurance benefits.

${ }^{5}$ We have checked average compositional values for the individual sample. No statistically significant differences prevail.
} 
To motivate our differences-in-difference strategy we display the development of log duration for treated an untreated in Figure 1. The trends are similar between the groups up until 1987, but after the reform the duration increases for those treated relative to the untreated.

Figure 1. Average log duration: Comparing treatment and control group for the period 1986-1990.

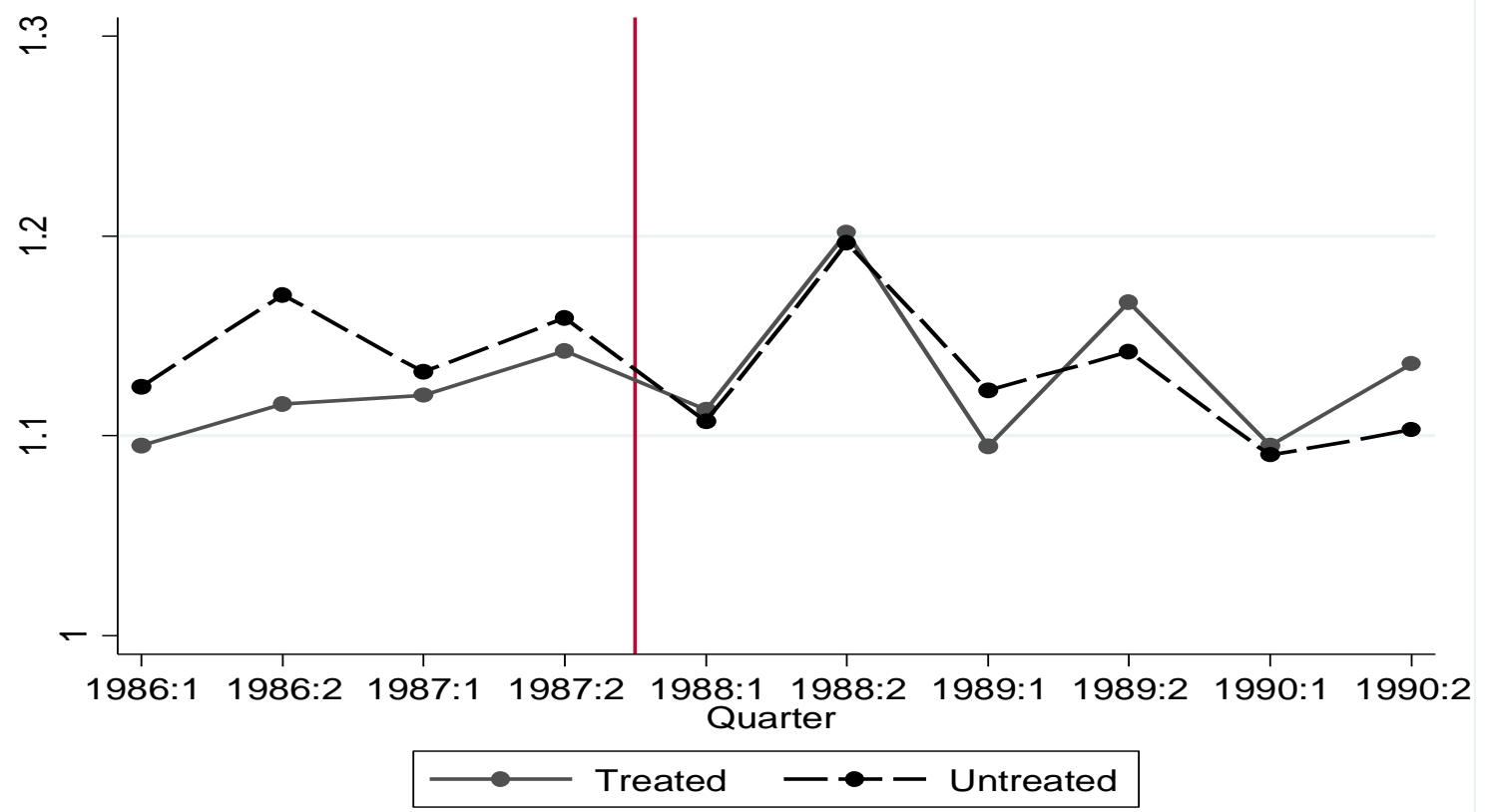

The direct effect of the reform is investigated by Pettersson-Lidbom and Skogman Thoursie (2010). They show that the reform increased the incidence by 11 percent while it decreased duration. This is not surprising since the reform made it less costly for a worker to be absent for short periods once the waiting day was abolished. In fact, the net effect of the reform on the total number of days of sickness absence was a 3 percent reduction. However, it important to note these types of incentives were not present for the population we studied in this paper since they were only indirectly affected.

\section{Estimations and results}

Our first analysis explores the distributional effects on duration by estimating the following linear probability difference-in-differences (DD) model:

$$
P\left(Y_{i g t} \geq s\right)=\alpha+\lambda_{t}+\pi D_{g t}+\delta_{s}\left(D_{g t} \times \text { Post }_{t}\right)+u_{i g t}
$$


in which $Y_{i g t}$ takes the value 1 if spousal $i$ is married to a treated partner ( $g=l$ and $O$ otherwise) at time $t$ and has a sick spell of at least $s$ days $(s=1,2, \ldots, 100)$. Time effects are represented by $\lambda_{t}$ ( $t$ is defined as half-years), $D_{g t}$ indicates whether the spouse is married to a treated partner or not and Post takes the value 1 from December 1987 ( $O$ otherwise). $\delta_{s}$ measures the average reform effect on the probability that sick spells lasted at least $s$ days. If the reform affected spouses' probability to start a new spell, we expect a positive DD-estimate at the threshold 1, i.e., $\delta_{1}>0$. If duration was affected, we should obtain significant effects at thresholds of higher orders.

Figure 2 displays the DD-estimates. The reform had no impact on the probability to start a sick spell; the effect is insignificant at the threshold 1. But it increased the duration of ongoing spells up to around 40 days, with the largest effects for spells fewer than eight days; those days for which the reform de facto changed the replacement rate. One explanation for the lack of effect on incidence is that starting a new spell appears to mark a worse career signal than merely continuing an ongoing spell with an additional day. It clearly can be more costly for the employer to adjust work plans and find a substitute for a new sick case than for a person who has already been on sick leave for a while.

Figure 2. Estimated reform effects on the probability that a spell exceeds a given length with a 95 percent $C I$.

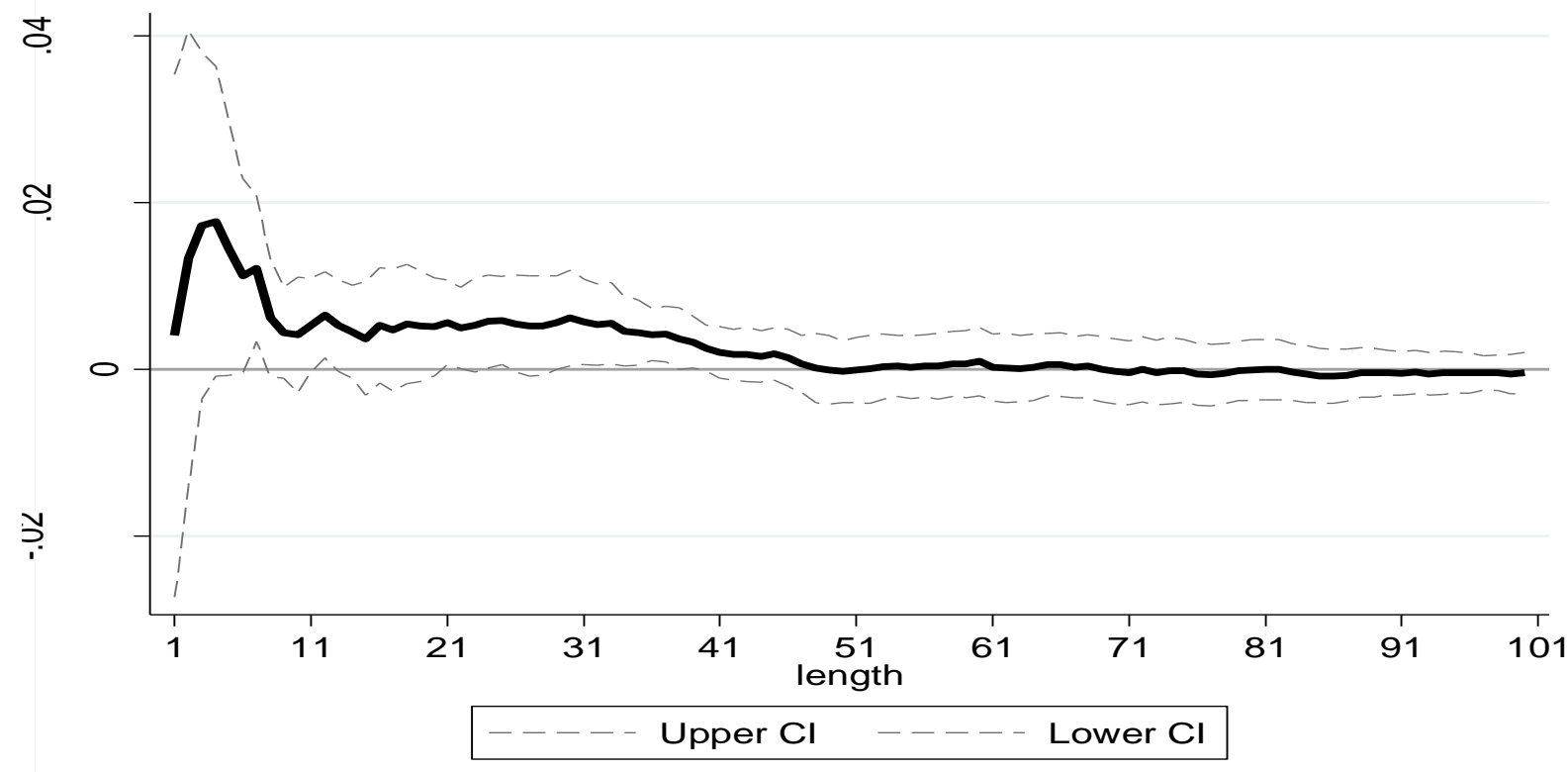

Note: Standard errors are clustered on a time-group level. 
The fact that incidence is unaffected by the reform increases our confidence in analyzing positive spells. We proceed to right-censor these at 50 days to avoid influences from extreme outliers, employing the following DD regression model:

$$
Y_{i g t}=\alpha+\lambda_{t}+\beta X_{i t}+\pi D_{g t}+\delta\left(D_{g t} \times \text { Post }_{t}\right)+\varepsilon_{i g t}
$$

$Y_{i g t}$ is log duration of sick spells, and $X_{i t}$ are individual covariates included to both improve precision and control for any potential composition changes. ${ }^{6}$ The total causal reform effect on duration, $\delta$, measures whether spouses to treated partners changed in durations after the reform relative to spouses with untreated partners. We decompose this total income effect into three parts. First, we ignore spells for couples that overlap in time ( 8.4 percent of the total sample) in order to evaluate the relative importance of a joint leisure effect. Second, we separate out the direct income effect by estimating equation (2) controlling for partners' income. ${ }^{7}$ Since partners' income is endogenous, we instrument this variable with the partners' pre-reform income in 1986 using 2SLS.

The results are reported in the first column of Table 2. The estimated total effect reveal that spousal duration significantly increased by 3.2 percent when partners received a higher sickness benefit. Omitting couples with overlapping cases doesn't change this result, making it more reasonable to ignore the endogeneity with joint leisure. When we control for the partner's income the effect is reduced to 2.6 percent, implying that the direct income effect is 0.6 percent. $^{8}$ We conclude that generally the insurance income effect is highly relevant for spousal labor supply.

To quantity the effect we reestimate the model using only treated spouses married to local governmental workers, as we know that their replacement rate increased by 11 percent. $^{9}$ The estimated effects are reported in the second column of Table 2. The total reform effect is 4 percent, implying an elasticity of spousal sick reporting with respect to the partner's benefit of 0.36 . The insurance effect is estimated to be 2.5 percent implying, an insurance elasticity of 0.23 .

\footnotetext{
${ }^{6}$ The covariates are age, whether the spouse is a wife, living in an urban area and household size. Including these covariates hardly change the estimated reform effect.

${ }^{7}$ It should be noted that a direct income effect is potentially relevant because we found evidence that partners' income was affected by the reform.

${ }^{8}$ The instrument has a t-value of 537 in the first stage.

${ }^{9}$ For workers above the income cap the change in replacement rate is smaller. This group is less than 5 percent of the sample, and the reform effect is unchanged when they are excluded.
} 
Table 2: Differences-in-difference estimates of the reform on log duration

\begin{tabular}{lcc}
\hline & Full sample & Local government workers \\
\hline Total Income Effect (IE) & $0.032^{* *}$ & $0.040^{* *}$ \\
& $(0.016)$ & $(0.018)$ \\
Ignoring cases with overlap & $0.032^{* *}$ & $0.039^{* *}$ \\
& $(0.016)$ & $(0.018)$ \\
Effect excluding direct income & $0.026^{*}$ & 0.025 \\
effect (IV) & $(0.016)$ & $(0.018)$ \\
Relative size of insurance IE & 71.2 & 62.5 \\
(share of total effect) & & \\
\hline Observations & 135523 & 81620 \\
\hline
\end{tabular}

Robust SE clustered on firm. All models control for county, age, sex and household size. When ignoring overlapping sick cases the sample size is 124,165 for the full sample and 74,214 for local government workers.

Finally, we estimate separate reform effects for low- and high income partners. The results (available from the authors upon request) show that spouses of low income partners reacted more to the reform than those of high income partners. This strengthens the finding that the insurance income effect is important, which is not surprising inasmuch as the need to insure against future economic shocks is likely to be higher for low income families.

\section{References}

Ashenfelter Orley. 1980, "Unemployment of Disequilibrium in a Model of Aggregate Labor Supply," Econometrica, 48, 547-564.

Autor, David H., and Mark G. Duggan 2007, "Distinguishing Income from Substitution Effects in Disability Insurance," American Economic Review, 97 (2), 119-124.

Cullen, Julie B., and Jonathan Gruber. 2000. "Does Unemployment Insurance Crowd out Spousal Labor Supply?” Journal of Labor Economics, Vol.18, No. 3, pp. 546-72.

Edin, Per-Anders, and Peter Fredriksson. 2000. "LINDA - Longitudinal INdividual DAta for Sweden." Working Paper, Uppsala University.

Heckman James J., and Thomas T. MaCurdy. 1980, "A Life Cycle Model of Female Labor Supply," Review of Economic Studies, 47, 47-74.

Krueger, Alan, and Bruce Meyer. 2002. "Labor Supply Effects of Social Insurance." In Handbook of Public Economics, vol. 4, edited by Alan Auerbach and Martin Feldstein, Amsterdam: North Holland, 2002.

Lundberg, Shelly J. 1985. “The Added Worker Effect.” Journal of Labor Economics, No. 3, pp. 11-37.

Pettersson-Lidbom, Per, and Peter Skogman Thoursie. 2010. "Temporary Disability Insurance and Labor Supply: Evidence from a Natural Experiment." Working Paper, Stockholm University. 